\title{
A DISCUSSION OF THE CONTROLLING PRIN. CIPLES OF BUILDING HEIGHT LIMITATIONS FOR GREAT CITIES
}

The proposal to limit the heights of building in New York City is nothing more or less than a proposal to limit the population of certain districts within the city. To those citizens who measure worth in material terms or greatness by numbers, this idea may not prove an acceptable procedure, nor is it likely to be welcomed by the great number of real estate speculators who have profited by the present congested conditions, without due respect for the welfare of the community as a whole.

To all patriotic citizens, however, who are unwilling to profit at the expense of the community, this step of limiting building heights has come to be realised as imperative, instead of merely advisable.

The city which has limited its bounds vertically as well as horizontally, like all things finite, has consequently limited capacity for population and for traffic. And this brings us at once to the question in handwhat shall this limitation be? What are the essential factors in the equation that is to determine the economic limitation-not merely to determine for the present, but for all time? Is it possible to determine such an equation, and in what manner shall its factors be derived and their relative importance ascertained ?

The paramount considerations which have brought about the enactment of statutes limiting the height of buildings in the principal cities of the world were, first hygienic and second æsthetic.

A third consideration which should have been taken account of and given great weight, but which has as yet had little or no influence upon height limitation statutes, is that of the utilitarian, which, in this problem, means nothing more or less than the consideration of all the traffic problems.

That the fundamental character and importance of traffic investigation has been almost totally disregarded, is in part evidenced by the great variance in the height established for building limitations in the important cities of the world, which in spite of a wide latitude of conditions existing in those cities, could hardly have occurred had there been a scientific basis for determining proper building heights. Such arbitrary conclusions as have hitherto been reached will be of no permanent value, as this is simply and purely a scientific problem.

At this point it is worth while noting why traffic considerations have not 
hitherto been factors in determining height limitations. It is perfectly clear that, as in early times, structural methods have not made possible tall commercial buildings, congestions due to traffic have not yet arisen, and concern as to the health of the citizens was at that time the sole consideration then in force. It is known that London, because of the ravages of pestilence generally prevailing and the high death rate, had great concern 'as to the health of its citizens, and one remedial measure limited the height of buildings to one and one-half times the width of the street for purposes of protecting the sources of light and air and thereby consequently the health of the community.

It was logical that æsthetic considerations did not follow until the city had reached self-consciousness as to its importance and size. These æsthetic motives have been of only fairly recent influence in height limitation throughout the world. The neglect, however, of traffic consideration is readily explained by the still more recent origin of the use of steel-frame construction, supplemented by the tremendous development of elevator engineering. These two factors, combined with the very rapid industrial development of our cities, have only recently begun to reap its by-product of traffic congestion, since at first a few tall buildings, somewhat scattered throughout the city, did not in themselves produce this congestion. Although many of our cities have had tall buildings for nearly two decades, they have hitherto been confined first to use as office buildings, which merely results in one kind of the less serious congestion of traffic, and second to lofty buildings which at first were spread over a considerable area, and were such a very small part of the entire developed area of the city that a new congestion resulted. Therefore congestion began to become serious only when the tall buildings began to spring up in groups and in large numbers throughout the city.

Now, however, here in New York we have for some time been face to face with a serious congestion of traffic, which has caused and is causing a great economic loss to this city, and which, if not shortly provided for by the proper limitation of the heights of buildings and other methods of procedure, or similar ones as is hereafter recommended, will place a still greater economic handicap upon the entire community. In fact it might be even asserted that this phase of the problem is so momentous and so absolutely essential as a primary consideration that even when scientifically and exhaustively studied, it is doubtful if the resultant conclusions will be more than slightly modified by hygienic or æsthetic consideration.

That this is an effort of enormous proportion should not daunt us, for by the solution of this problem we will be rewarded with having made possible the maximum economic efficiency which is inherent to 
the city. Incidentally New York will have the honour of leading the world as a reward for the courageous and persistent effort which the solution of this problem most certainly demands. Were it not for the temper and personnel of the committee which has been appointed one would hesitate to present the scientific phases as herein amplified, but I am convinced that this committee has been determined to delve to the very bottom of this question, and will not be satisfied merely to follow the example of other cities but rather is determined to lead the way in solving the problem and to fortify itself for making what will prove to be the very best recommendation as a basis for legislative enactment.

In the logical order of procedure to the solution of this problem the first step must be to delineate in a tentative way the boundaries of those districts of the city in which all the economic functions of the same or allied type, such as logically would be classified together, may conveniently be grouped. These districts or zones, tentatively defined, should be classified as follows:-

(a) Business.-(1) Industrial, (2) commercial, (3) wholesale, (4) retail.

(b) Residential.-(1) Apartments, (2) tenements, (3) private houses.

(c) Civic.-(1) Federal, (2) municipal, (3) educational, recreational.

The boundaries of these zones may be determined with a sufficient degree of accuracy for the preliminary steps by an examination of the rate of growth, for example, of the commercial and the wholesale districts. The determining factor of these tentative boundaries is the rate of growth of the contiguous zones of different classification. This means the horizontal rate of growth, but ultimately the final zone boundary will be determined by the consideration of the vertical in conjunction with the horizontal growth. This explains the necessity of establishing only tentative zone boundaries.

The next step would be to determine the ultimate traffic capacity of the streets of the tentative zone of the future city. Traffic capacity or traffic load may be defined as that amount of vehicular, pedestrian, and street-car upper and sub-traffic which will yield the maximum economic efficiency to the city as a whole. This ultimate traffic capacity depends, as far as the zone in question is concerned, upon three things: First, upon future traffic regulation; second, upon the design of the street section; third, upon the ultimate advisable width of the street; and fourth, upon the nature of the traffic which the zone in question yields.

It would be impossible here to give an exhaustive consideration to any one of the headings, but it will suffice to give a few examples to 
illustrate the character and potency of each of these factors in determining the traffic load of any business zone.

Although the citizens of New York have had some illustrations of the advantages of traffic regulations, they have as yet experienced little as compared with what will ultimately be enacted into statutes.

Perhaps the most fundamental regulation that is certain to be realised is that of the establishment of a uniform gauge or width for all vehicles; without such a uniform width of vehicle it will be impossible to establish a sufficiently exact standing and moving traffic unit upon which must be based our calculations for the traffic capacity of streets. It is even possible also that a maximum and minimum length of vehicle may ultimately be found desirable. This line of procedure is likely to eliminate the horse-drawn vehicle on account of its occupying a space two-fifths longer than the motor-driven vehicles. It can be seen, then, that here a very large increase of street traffic capacity can be ultimately made by such regulations.

It will be advisable soon to erect a statute that will enforce the close standing of all resting vehicles to within six inches of, and parallel to, the street curb, also that vehicles shall not stop so as to leave less than the minimum traffic unit between itself and the vehicle in front of it with the exception being made for vehicles that come to a stop occupying the entire space up to the next standing vehicle.

The next regulation that is likely to be considered will be the establishing of a minimum and maximum rate of movement for vehicles in certain streets. The rate will be determined scientifically and will be partly determined by the length and width of streets. A minimum restriction in the rate of movement may be found to be quite as essential for establishing the maximum economic efficiency as will a maximum restriction for preventing danger to pedestrians. The rate of movement permitted for a given street determines the moving traffic unit for that street, as it is evident that the vehicle moving slowly will need less room in reference to passing, standing, or moving vehicles, than one which moves at a higher rate of speed.

Another regulation that will ultimately be used for increasing the traffic capacity of a street will be that of confining either the loading or the unloading of vehicles to within the private property lines. The lack of this regulation is one of the most serious causes of present traffic interruption and limitation, not only in the wholesale and commercial districts, but also in the retail districts where large department stores block the street almost completely on the side on which they load, with great detriment to the opposite property.

Another traffic regulation will undoubtedly be in some instances 
helpful, that is in making short streets one-way traffic streets, thus avoiding passing of vehicles moving in opposite directions. It may also be found that some regulation of the same type may be found desirable for the main traffic arteries of the city, such as, for instance, of restricting Fifth Avenue to all down traffic in the morning and to all up traffic in the afternoon, and vice versa with Sixth Avenue and Madison Avenue, but the details of such a provision would have to be very exhaustively studied before the promulgation. of such an arrangement could be undertaken without menace to the vast property interests involved.

Still another regulation for the main traffic arteries of the city which may be used to increase their capacity will be the establishing of a semaphore system of signalling, for instance, for Fifth Avenue, which would make possible the simultaneous stopping of all side street traffic for the entire length of the business part of the avenue. This would be a great advantage in increasing traffic capacity, since it would protect the continuous flowing of traffic from block to block for definite periods of time (such as on examination would prove the most advantageous periods), and thus increase the rate of movement which more than anything else means the amount of traffic capacity.

It may be that we are even coming to the time when all cross traffic will be passed under the main up and down thoroughfares with an arrangement on all centred streets for ramping up into these thoroughfares from the side streets. If such a scheme were ultimately adopted it would be supplemented by the restricting of all up traffic to the entering of the avenue from the east and restricting of all down traffic to entering the avenue from the west. The regulations that have been so far discussed have dealt only with that of vehicle traffic, but pedestrian traffic is in some respects a more serious factor in our present-day congestion than the vehicle congestion.

It is conceivable that the regulation of this traffic congestion is of sufficient importance to establish a traffic entrance in charge of a traffic bureau in all of the business zones of the city, which bureaus would be part of a traffic bureau system having one competent man in charge of the whole. One of the results of the study and announcements of traffic conditions of all the respective zones would be that proper regulations could be devised which would control the number of employés that it would be permissible for a given zone to receive or discharge during a given period. This control would be based upon the maximum hygienic traffic capacity of the various transportation agencies tapping the different zones. It would be expressed by restrictions, for instance, which, instead of permitting, as is now the case, the discharging of the majority of 
employés of a factory or store at the same time, it would insist upon this discharge spreading over that period of time which would not result in the congestion of pedestrian traffic either in the streets or on any of the transportation agencies.

By similar procedure and restriction congestion at given hours of the day of vehicle traffic may also be avoided, and so avoid the necessity of using the maximum traffic load of a given hour as the controlling basis in our deductions for determining the maximum economic traffic permissible for given streets. If such restrictions prove feasible this traffic capacity of a given street will be materially increased.

These considerations of traffic regulations have been expounded at length, because no final height limitations can be established without closely anticipating what these traffic regulations are to be, since they have such a vital influence upon the ultimate economic traffic known that a street can carry.

The second main consideration affecting a street's capacity for traffic is that of the design of the street section, i.e., its proportion of sidewalk to roadway. This would be first accomplished by an examination of the proportion of congested traffic which a given type of zone yields to the street. The street must then be divided to carry efficiently both the congested and vehicle traffic according to the proportions that the investigation of the zone business determines is the correct one. The details of these dimensions will be determined by the number of standing and moving traffic units that this zone demands, but these units must be the basis of the width of the vehicle roadways. In the same manner the average width of the pedestrian by the units upon which the width of the sidewalk is to be exactly determined. It will be seen that this procedure will be extensively efficient because of allowing no unnecessary space in the streets that cannot be used as is now the case and which often is the cause of the wedging and consequently the holding up of the floor traffic. In some zones, such as the wholesale produce zone, the present system of backing up the vehicles for a moment results in pedestrians walking through the middle of the street. This suggests that even if a restriction enforcing the loading and unloading of vehicles within property lines is enacted, that a sidewalk or rather a centre walk in the middle of the street might advisedly replace the two sidewalks. This suggestion would have the advantage of dividing the traffic moving in opposite directions. Another street section which might prove advantageous in stricting office or financial districts would be to do away with all curbs and to take care of the drainage which the curb now takes care of by throwing the water to the centre of the street and by supplementing the drainage system by the using of more frequent 
intakes. This street section would involve, of course, the elimination of vehicle traffic at the busy times of the congested traffic.

This brings us to the last main heading under which the methods for increasing the economic traffic load to its maximum has been discussed, that is, the final street width.

Many streets will be found to be improved either on the one or both sides with non-permanent buildings. Wherever this condition is found in the given zone, the best economic width for the street should be forthwith determined. This can only be best determined by a consideration of the problem as a whole, and conjectures will have to be made as to what will likely be the most economic width. Upon the assumed desirable ultimate width we must in part base our conclusions as to the ultimate traffic load that will be found permissible to carry. The individual property owners along a street having one or both sides free from permanent improvements will find it advantageous to conform without undue delay to the newly established building line for the street in question rather than to remodel an old building of limited capacity, since with the restrictions to the new building line also will go the privilege of a material increase in height of a building that will be permissible.

We have now weighed the three essential and primary factors that will affect the ultimate traffic capacity of the future streets, and therefore are ready to deduce from these considerations what the maximum economic yields of a given street will be. Having computed this traffic capacity, the next step will be to determine the amount of traffic which a given square foot of floor area for a given zone will yield in pedestrian and vehicle traffic. By dividing this amount of traffic into the traffic capacity of the street as a whole, the number of units square foot floor area will be the quotion; but as the ground space adjoining a given street is a limited quantity, this quotion determines the number of floors and consequently the height of buildings which is the most economic for business zones which we have been discussing. Since this, is the crux of the method recommended for determining the height of buildings for the four types of zones coming under the head of business zones it might be somewhat illustrated by putting it in the form of an equation as follows :-

$\mathrm{Y}=$ Maximum economic traffic known permissible for a given street.

$\mathrm{Z}=$ Amount of traffic which is the average yield for 1,000 square feet of floor area of the zone in which a given street is located.

$\mathrm{Y} / \mathrm{Z}=$ The number of 1,000 square foot floor-area units which are economically permissible to the street in question.

The foregoing conclusion will have to be modified if it is based on the tentative zones as has been suggested since the final delineation of the 
zones determines the amount of traffic which that zone yields. Slight modifications for hygienic reasons may also be found necessary as has before been admitted, should the resultant building height of this equation become excessive, so as to shut out essential light and air. Here it might be observed that the detriment to health which has been laid to tall buildings and the resultant need of artificial light also to unsatisfactory ventilation. These difficulties have been greatly exaggerated and can probably be for the most part eliminated by regulations that will provide the best system of ventilation and of artificial light now in use, and by setting a time limit for the use of those buildings not now being adequately equipped with proper lighting and ventilating systems.

The final zone boundaries will be determined by the examination of the amount of traffic that each zone contributes to the city as a whole, but more especially by the announcements of the rate of growth, and to the direction of growth whether horizontally or naturally that each zone will make. Where adjoining zones meet as a result of this expansion will be the proper boundary to be established.

It may be well to observe here that provision must be made for the time, when these zones will have reached their maximum capacity on account of height limitation and traffic regulation. The provision which might be most efficacious would be that of establishing zones in out-lying districts, designed to take the surplus. Here should be found the most scientific development of zones according to their various functions, taking as a guide for the type of zone to be established in a given location, the existing neuclei of development as the determining indication of the probable type of development. This procedure, it will be seen, will anticipate the needs of the city when the zones of the city proper have reached their maximum economic limit of development.

After the traffic load for each separate tentative zone has been determined, we must determine what part of the zone traffic will be emptied upon the general traffic arteries of the city. Although it is feared that much of the zone traffic will be carried on within the zone itself, a certain percentage of it will be emptied upon the major traffic arteries, therefore it is essential to discover whether or not the volume of inter-zone traffic along major arteries would be in excess of the maximum economic efficiency of these thoroughfares. Should it be found in excess of the efficient capacity of these streets, the amount of the traffic from various zones must be decreased to appoint where the traffic yields of all the zones to the main arteries will be no more than these main arteries can economically handle. This curtailment of traffic yield to the main arteries from the zones will be accomplished by cutting the height of the 
buildings in the various zones to below a point previously determined by the traffic capacity of the individual zone.

The foregoing observations conclude the discussion of the controlling factors for determining the height of building for the four zones classified under the general heading of business zones, i.e., commercial, industrial, wholesale, and retail, and this brings us to the discussion of the second main classification under which the discussion of the subject has been placed, i.e., residential zones.

On account of the fact that much more careful consideration has been given to the controlling factors for limiting the height of buildings in residential and civic zones, this paper is giving only a relatively brief consideration to these two sub-divisions of the problem.

Residential zones may be appropriately classified as before indicated into the following sub-headings:-

(1) Apartments.

(2) Tenements.

(3) Private houses.

We have previously noted that there are three controlling considerations in the determining of proper height of building for a great city, which are, first utilitarian, second hygienic, and third æsthetic. While the foregoing is given in the order of their relative importance for business zones, this order changes for both the residential and the civic zone and becomes for the former, first hygienic, second æsthetic, and third utilitarian. For the eivic zones the order of the importance of these considerations again changes and becomes first æsthetic, second utilitarian, and third hygienic.

It is self-evident that for the residential zone hygienic considerations must be the vital and primary considerations in the determination of the proper height of buildings. This in other words means the protection of the sources of light and air. This seems to be the phase of the subject which has been given the most scientific consideration, but nevertheless the possibilities of this aspect of the question is far from being exhausted. A paramount consideration, for instance, is that of the angle at which the sun's rays becomes a hygienic factor, but this, however, must be the average angle at which the sun's rays are effective for an entire year. Upon this factor more than any other rests the solution for the proper height limitation of a residential community in a built-up city.

In undeveloped residential zones which are ultimately to become closely built-up residential sections, the proper direction of streets which determine the orientation of city 'blocks becomes the most important medium, except that of actual height limitation, for effectively and properly protecting the sources of light and air. An illustration of this 
contention is found here in Manhattan Island, where the worst possible block orientation has resulted on account of the original designers of the city plan to facilitate expeditious access to both the East River and the Hudson River. This undoubtedly was a desirable object, since in the days when the initial plan was made, water traffic was the principal means for carrying on trade and commerce. Specifically the outcome of this design has been that approximately half of the residential frontage of New York City is without sunlight during those six months of the year when the need of it is most vital to the health of the citizens.

There is a possible modification of these long east and west blocks which may be affected by the use of height of building regulations. Reference is made to the suggestion of dividing the long blocks with a park and sidewalks and then converting the real yards into public courts with grass space in the middle. Where this could be advisedly undertaken a higher residential building could probably be hygienically permitted.

Traffic and æsthetic considerations in relation to residential zones are only secondary and minor considerations, because the proper width of street necessary to effectively and permanently secure the essential hygienic results in conjunction with height of building limitation will prove in every instance adequate to meet the utilitarian and æsthetic needs of this type of zone. The third main type of zone which has been designated as civic has, as a primary consideration, neither the utilitarian as in the business zone nor the hygienic as in the residential zone, but rather the æsthetic. Here it should be explained that the use of the word zone has not been meant to define any one section of the city, but rather an area of influence of a given city function, and as such one zone might be found within another and similar type zone near by but separated by another type of zone.

In the case of the civic zone the area of influence which the height limitation regulation would affect is likely to be relatively restricted, although its influence should extend considerably beyond the group of buildings comprising such a zone.

The primary functions of such a zone must be the furnishing of such sites for public and semi-public institutions as will give the most beautiful and dignified results. Such provision will invariably provide sufficient space for all traffic needs and will at the same time meet the hygienic demands.

The proper extent of the setting most desirable for a group of public buildings depends upon the scientific phase of the question which has been given but little attention. Reference is made to that optic angle at which a group as a whole of important buildings may be most effec- 
tively viewed. As this angle varies more or less with each individual the average angle must be the one to be used. This has been determined to be approximately $27 \frac{1}{2}$ degrees. Of course in the matter of great towers or spires this angle does not need to be considered, since a momentary lifting of the head is anticipated as necessary, but in the mass of buildings comprising a group it should be the æsthetic goal that these buildings may be conceived with their greatest effectiveness without involving a conscious effort.

A great æsthetic loss has hitherto been caused by failure to give due consideration to this aspect of this problem. Much expenditure has been made for æsthetic effect of important buildings, but has been entirely lost through inadequate site, which fails to give the view-point with the optical angle herein asserted as essential. In the permanently built-up sections of the city, such as the City Hall Square, this principle can only be applied in part to the height of entrances or to the treatment of the first few storeys of the building on account of the excessive height and the lack of the proper amount of setting to perceive the building or buildings as a whole or in a group. This, however, will not prove true of the proposed civic centre, which should be designed in a manner conforming to the scientific principles herein stated, as should all other newly developed civic groups such as come under this heading.

\section{Conclusion}

The following are the conclusions derived from the foregning contentions :-

(1) The height of building must be limited.

(2) The extent of the limitation must vary according to the functions of the different parts of the city.

(3) The maximum economic traffic load which the business zones of a city and their arteries can carry will determine the various heights of the commercial, industrial, wholesale, and retail sections.

(4) This in turn depends upon anticipating all the possible mediums for increasing traffic capacity such as :-

(a) Traffic regulation.

(b) The designing of the considered section.

(c) The final width of the street.

(5) The higher buildings may be permitted, in a given street, when abutting property owners will agree to widen the street sufficiently to accommodate the increased traffic of higher buildings.

(6) That the hygienic consideration of the angle at which the sun's rays becomes an effective hygienic factor, is the dominant factor in 
determining the proper height of buildings in closely built-up residential districts.

(7) In unbuilt-up districts the orientation of the block in conjunction with the effective angle of the sun's rays will be found the controlling principles in determining the height limitation to be established for such a section when fully developed.

(8) That æsthetic motives must be the dominant factor in determining the height of building for public or semi-public groups. That the most important factors in the limitation of the height of such groups of buildings is the vertical optical angle at which the average individual readily conceives an object.

(9) That immediate study of traffic capacity of congested zones of the traffic yields from given districts from a unit amount of floor space should be determined.

(10) That an investigation should be made into all possibly advantageous traffic regulations; for instance, such as have herein been suggested, in order to determine at once the future maximum economic traffic load that the presently congested districts will be able to carry without such regulations as are found advisable may become operative.

Robert Anderson Pope. 